\title{
The Current Status of Germplum Database: a Tool for Characterization of Plum Genetic Resources in Romania
}

\author{
Monica HÂRȚA ${ }^{1}$, Cristian Radu SISEA ${ }^{1 *}$, Rodica POP ${ }^{1}$, Katalin SZABO ${ }^{1}$, Maria ZĂNESCU ${ }^{1}$, Doina CLAPA ${ }^{1}$, \\ Dorothea DOMOKOS ${ }^{1}$, Mihai BOTU², Doru PAMFIL ${ }^{1}$ \\ ${ }^{1}$ Faculty of Horticulture, University of Agricultural Sciences and Veterinary Medicine, 3-5 Mănăştur \\ Street, Cluj-Napoca, Romania \\ ${ }^{2}$ Faculty of Horticulture, University of Craiova, 13 A.I. Cuza Street, 200585, Craiova, Romania \\ *)Corresponding author, e-mail: cristisisea@yahoo.com
}

BulletinUASVM Horticulture 73(2) / 2016

Print ISSN 1843-5254, Electronic ISSN 1843-5394

DOI:10.15835/buasvmcn-hort:12324

\begin{abstract}
In Romania, Prunus genetic resources are kept in collections of varieties, populations and biotypes, mainly located in research and development institutes or fruit growing stations and, in the last years, by some private enterprises. Creating the experimental model for the Germplum database based on phenotypic descriptors and SSR molecular markers analysis is an important and topical objective for the efficient characterization of genetic resources and also for establishing a public-private partnership for the effective management of plum germplasm resources in Romania. The technical development of the Germplum database was completed and data will be added continuously after characterizing each new accession.
\end{abstract}

Keywords: characterization, database, genotypic, phenotypic, plum

\section{Introduction}

Conservation and utilization of genetic resources depends largely on the availability of information regarding phenotypic and genotypic characteristics of the species of interest (Rao and Hodgkin, 2002). Plum is considered the second most important fruit tree crop in the temperate climate regarding the production. The plum fruits have been used extensively during history as healthy fresh or dried food, but also processed as jam, marmalade, jelly and brandy (Botu et al., 2012).

In Romania, Prunus genetic resources are kept in collections that include wild species, local populations, cultivars and rootstocks of $P$. domestica, $P$. salicina and P. cerasifera. These collections are located mainly in research and development institutes or fruit growing stations. In the last years, some of the public holding institutions were reorganized and the number of plum accessions dramatically decreased. Also, there is a growing interest of private enterprises to establish their own on farm collections and fruit tree nurseries with native biological material for the purpose of multiplying valuable autochthonous varieties (Botu et al., 2012).

\section{Aims and objectives}

Creating the experimental model for the Germplum database based on phenotypic descriptors and SSR molecular markers analysis is an important and topical objective for the efficient characterization of genetic resources and also for establishing a public-private partnership for the effective management of plum germplasm resources in Romania.

\section{Materials and methods}

Phenotypic description was based on EURISCO Multi-crop Passport descriptors (www.ecpgr. cgiar.org). Ten primer pairs (pchgms1, UDAP404, 


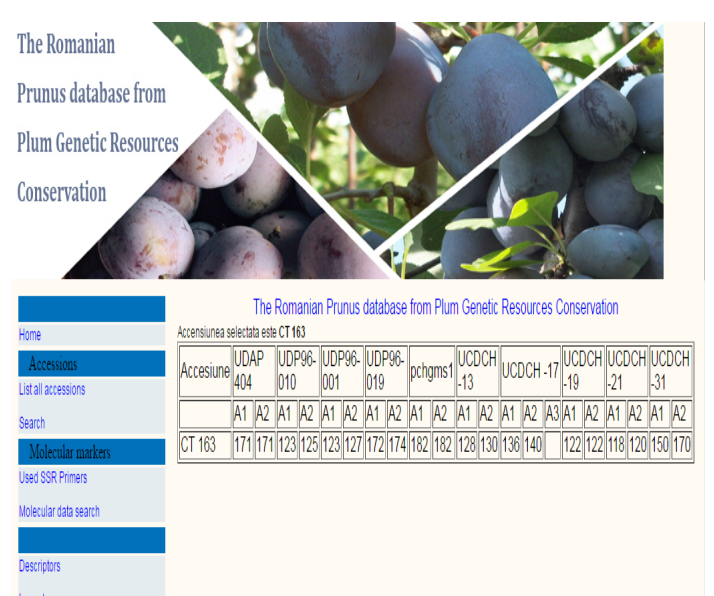

Fig. 1. SSR characterization for accession CT-163

UDP96010, UDP96001, UDP96019, UCDCH13, UCDCH17, UCDCH19, UCDCH21, UCDCH31) and previously published protocols (Bodea et al., 2016) were employed for the SSR analysis. An open source relational database management system, MySQL-5.1, was used for designing the database, while the PHP tool was utilized for scripting language (Ivaşcu, 2005).

The experimental model for the Germplum database is hosted on the web server ns.usamvcluj. ro (http://www.usamvcluj.ro/GERMPLUM/database/login.php).

\section{Results and Discussion}

The number and size of identified alleles obtained for each SSR primer pair suggested a complex structure for each of the 87 local plum accessions analyzed. Characterization of varieties with a set of 35 general and specific phenotypic descriptors indicates a heterogeneous genetic material that can be exploited in future breeding activities.

The database will have two levels of access, public and private. Currently, only the access to chosen descriptors, e.g. molecular data (Fig. 1.), is available, for registered users, based on ID and password (Fig. 2.).

The main features that Romanian Prunus database offers is searching for molecular and phenotypic information on documented accessions, comparing phenotypic (including images) and/or molecular data among several accessions and exporting molecular data in compatible formats for different genetic analysis software.

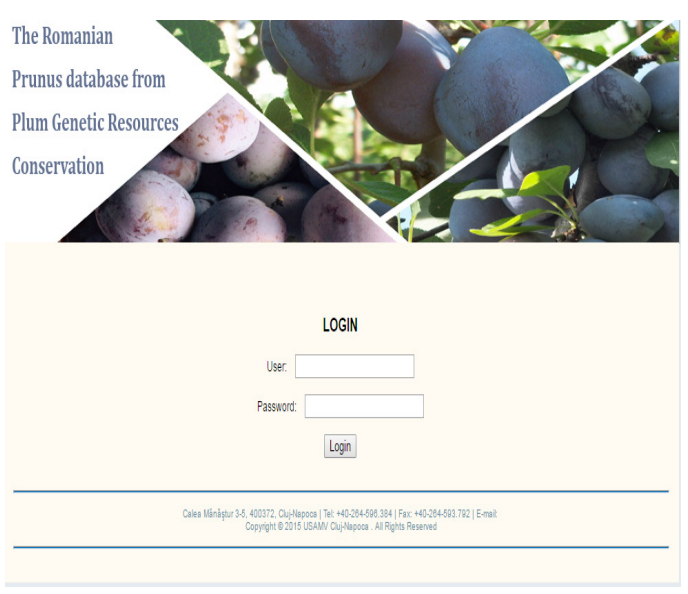

Fig. 2. Prunus database access based on ID and password

\section{Conclusion}

The development of the Germplum database platform was completed and data will be added continuously after characterizing each new accession.

Creating the Romanian Germplum database is an important aim for increasing the efficiency of characterizing genetic resources and preserving germplasm for future generations.

Aknowledgement. This paper was published under the frame of PN-II-PT-PCCA-2013-2014, project no. 168/2014.

\section{REFERENCES}

1. Bodea M, Pamfil D, Pop R, Sisea RC, (2016). DNA isolation from desiccated leaf material from plum tree (Prunus domestica L.) molecular analysis. Bull. UASVM CN 2016(1):1-2.

2. Botu I, Botu M, Papachatzis A, Cosmulescu S, Preda S, (2012). Evolution of plum culture; constrains and perspectives . Acta Hort. (ISHS) 968: 19-24.

3. Botu M, Tomić L, Hjalmarsson I, (2012). Balkan plum pomology. Review of the Monograph: 12-13, ISBN 97891-637-0272-3.

4. Ivaşcu V (2005). Inițiere în PHP\&MySQL: http://www. oriceon.com/

5. Rao VR, Hodgkin T, (2002). Genetic diversity and conservation and utilization of plant genetic resources. Plant Cel. Tissue and Org. Culture (68):1-19.

6. ***http://www.ecpgr.cgiar.org/fileadmin/templates/ ecpgr.org/upload/NW_and_WG_UPLOADS/Prunus / EPDB_New_list_of_descriptors_2011.pdf. 